\title{
Lateralization When Monitoring Predators in the Wild: A Left Eye Control in the Common Wall Lizard (Podarcis muralis)
}

\author{
José Martín^, Pilar López*, Beatrice Bonati† \& Davide Csermely $\dagger$ \\ * Departamento de Ecología Evolutiva, Museo Nacional de Ciencias Naturales, CSIC, Madrid, Spain \\ $\dagger$ Dipartimento di Biologia Evolutiva e Funzionale, Sez. Museo di Storia Naturale, Università di Parma, Italia
}

\section{Correspondence}

José Martín, Departamento de Ecología Evolutiva, Museo Nacional de Ciencias Naturales, CSIC, C/José Gutiérrez Abascal, 2. 28006 Madrid, Spain.

E-mail: jose.martin@mncn.csic.es

Received: July 19, 2010

Initial acceptance: July 29, 2010

Final acceptance: September 2, 2010

(K. Reinhold)

doi: 10.1111/j.1439-0310.2010.01836.x

\begin{abstract}
Lateralization is the function specialization between left and right brain hemispheres. It is now ascertained in ectotherms too, where bias in eye use for different tasks, i.e., visual lateralization, is widespread. The lateral eye position on the head of ectotherm animals, in fact, allows them to observe left/right stimuli independently and allows lateralized individuals to carry out left and right perceived tasks at the same time. A recent study conducted on common wall lizards, Podarcis muralis, showed that lizards predominantly monitor a predator with the left eye while escaping. However, this work was conducted in a controlled laboratory setting owing to the difficulty of carrying out lateralization experiments under natural conditions. Nevertheless, field studies could provide important information to support what was previously found in the laboratory and demonstrate that these traits occur in nature. In this study, we conducted a field study on the antipredatory behavior of P. muralis lizards. We simulated predatory attacks on lizards in their natural environment. We found no lateralization in the measure of eye used by the lizard to monitor the predator before escaping from it, but the eye used was probably determined by the relative position of the lizard and the predator just before the attack. This first eye used did not affect escape decisions; lizards chose to escape toward the nearest refuge irrespective of whether it was located to the lizard's left or right side. However, once they had escaped to a refuge, lizards had a left eyemediated bias to monitor the predator when first emerging from the refuge, and this bias was likely independent of other environmental variables. Hence, these field findings support a left eye-mediated observation of the predator in P. muralis lizards, which confirms previous findings in this and other species.
\end{abstract}

\section{Introduction}

Several studies have shown that many vertebrates are lateralized, i.e., have brain hemispheres specialized to control specific functions (Vallortigara $\delta$ Rogers 2005). As this phenomenon is often expressed as asymmetries in eye use, it is well evident in animals with a lateral position of the eyes (Andrew 1991). This is true for several taxa (Vallortigara \& Rogers 2005), of both ectotherms and endotherms, supporting the hypothesis that this character is inherited from a common vertebrate ancestor (plesiomorphic character) and is likely really advantageous for who presents it. Lateralized animals perform some tasks better than nonlateralized animals (Fabre-Thorpe et al. 1993; Rogers et al. 2004; Sovrano et al. 2005). Being lateralized, in fact, likely could provide several computational advantages such as avoiding the duplication of functions present in the brain hemispheres (Levy 
1977) and avoiding the 'functional incompatibility' (Sherry \& Schachter 1987) between answers simultaneously evoked by different stimuli perceived by the two different hemi-visual fields (Vallortigara 2000). Consequently, lateralized animals may be able to process information in parallel, obtaining the important advantage of carrying out more tasks simultaneously (Rogers 2002; Dadda \& Bisazza 2006).

In fact, whereas the right eye/left hemisphere seems involved in controlling feeding cues, for example in birds (Rogers 1997; Güntürkün \& Kesh 1987), anurans (Robins \& Rogers 2004; Robins 2006), lizards (Bonati et al. 2008) and fishes (Miklósi \& Andrew 1999; Lippolis et al. 2009), the right hemisphere is specialized in perceiving antipredatory, exploratory and aggressive cues, from the left eye input (Lippolis et al. 2002; Robins 2006; MacNeilage et al. 2009). This is true for birds, lizards, toads and fishes (Deckel 1995; Vallortigara et al. 1998; Vallortigara 2000; Reddon \& Hurd 2009), which could forage while simultaneously making predator vigilance and monitoring without constraining the performance of both tasks (Rogers 2002; Rogers et al. 2004; Dharmaretnam \& Rogers 2005; Dadda \& Bisazza 2006). This is an important advantage for survival that could increase the fitness of individuals that present this specialization. There are not many studies conducted on sauropsids, but some recent laboratory works showed that the common wall lizard (Podarcis muralis) uses preferentially the right eye/ left hemisphere in looking at the prey and the left eye/right hemisphere in predatory evasion and exploratory tasks (Bonati et al. 2008, 2010; Csermely et al. in press).

In this study, we investigated whether $P$. muralis lizards expressed lateralization of antipredatory behavior in the field. To assess risk, prey must be vigilant and observe (i.e., monitor) the predator, once it has been detected (Lima 1994; Wright et al. 2001; Cooper 2008). Monitoring is important to decide the approach or flight initiation distance from the predator when the escape begins (Cooper 2008; Martín et al. 2009), and it could be useful to assess risk of emerging from refuges (Cooper 1998; Martín \& López 2001; Polo et al. in press). Lizards have laterally placed eyes and one central fovea (Röll 2001). In the lizard Sceloporus virgatus, the approach distance is shorter in areas of limited acuity or behind and in front of them than with a lateral detection (Cooper 2008). Hence, lizards should prefer to monitor predators laterally and may benefit from being lateralized in this task.
All previous studies conducted on lateralization in sauropsids were made under laboratory conditions, and no field data exist about it. Thus, usually it is very difficult to know whether side biases caused by brain lateralization affect in any relevant way the behavior of animals in natural conditions (Ventolini et al. 2005; Koboroff et al. 2008). However, there is an increasing understanding that perceptual asymmetries are not confined to the artificial laboratory conditions, but they may occur in natural conditions too, especially in animals with laterally placed eyes, thus improving the study of lateralization in the field (McGrew \& Marchant 1999; Ventolini et al. 2005). Moreover, field studies not only would support laboratory data, but they are also important because finding that individuals from a natural population are lateralized would indicate that lateralization has been selected because it actually increases fitness of individuals. Nevertheless, lateralization could just be a by-product of neural wiring with no real function and could persist because it is not costly, rather than being fitness-enhancing.

Here, we simulated predator attacks in the field and examined (1) whether the eye used by P. muralis lizards to look at the predator before escaping affected escape decisions and refuge use and (2) whether lizards showed lateralization preferring one side (eye) in monitoring the potential presence of the predator before emerging from the refuge.

\section{Methods}

The common wall lizard (P. muralis) is a small lacertid lizard [60-76 mm adult snout-to-vent length (SVL)] widespread in central Europe. In the Iberian Peninsula, it is restricted to mountain areas of the center and north of Spain, where it occupies soil dwellings and rock walls in shaded zones in forests (Martin-Vallejo et al. 1995). We conducted the study during Apr. 2009, in a pine forest at Cercedilla, in the Guadarrama Mountains (Madrid Province, Central Spain) at an elevation of $1500 \mathrm{~m}$. The dominant vegetation consists of Pinus sylvestris forest, with shrubs such as Juniperus communis and Cytisus scoparius. We conducted the experiment on several granite rock artificial walls (each one measuring approximately $100 \mathrm{~m}$ long $\times 5 \mathrm{~m}$ high). At our study site, active lizards were usually found basking or walking on the walls and using the numerous crevices between rocks as refuges.

We searched for lizards by walking the area between 0700 and $1200 \mathrm{~h}$ (GMT). When we detected a lizard, we observed with binoculars which 
eye of the lizard was oriented toward the experimenter direction ('initial eye'). Then, we immediately approached the lizard simulating a direct predatory attack by walking directly and fast (approximately $140 \mathrm{~m} / \mathrm{min}$ ) toward the lizard and looking directly at it. To avoid other confounding effects that may affect the risk perception of lizards (Burger \& Gochfeld 1993; Cooper 1997b; Cooper et al. 2003), the same person wearing the same clothing performed all approaches in a similar way, while another person motionless helped to record data with binoculars from a hidden position behind a hedge of trees or bushes. Lizards typically made a short flight to the nearest available refuge (into a rock crevice) and hid entirely from the observer. We defined the 'approach distance' as the distance between the lizard and the observer when the lizard first moved (a straight line measured to the nearest $0.1 \mathrm{~m})$. We also determined the distance covered during active flight until the refuge ('distance to refuge') (Martín \& López 1995; Cooper 1997a). During approaches, we marked the position of the observer when the lizard fled by dropping a small marker on the ground and remembered the location of the lizard based on characteristic features of the wall. At the end of each trial, we measured distances with a metric tape.

When a lizard hid, the experimenter retreated to a distance of 5-7 $\mathrm{m}$ to observe motionless from a hidden position (behind a hedge of trees and bushes) directly in front of the lizard's refuge. We used this procedure to avoid that the position of the observer relative to a lizard emerging from a refuge in a wall (and therefore the eye facing the observer) was largely determined by the observer, not by the lizard. By standing in front of the refuge, we 'forced' the lizard to cock its head one way or the other (Cooper 2008). Lizards usually emerged partially from the refuge and turned the head or the entire body to scan outside with an eye before emerging totally. Thus, we were able to determine and noted the eye used by the lizard to scan in its first appearance, and we also recorded the time until the lizard's head appeared from the refuge ('appearance time'). A few observations where the scanning eye could not be unambiguously determined, or where the observer could have influenced scan behavior, were discarded.

Because environmental temperatures can affect antipredatory behavior by lizards (Martín \& López 1999a,b; Amo et al. 2003, 2004), we only made observations on sunny days and when ambient temperatures were optimal for lizard activity (i.e., air temperatures ranged between 18 and $26^{\circ} \mathrm{C}$ ). Field body temperatures of active lizards in this area ranged between 23.3 and $38^{\circ} \mathrm{C}$ (mean $=32.0^{\circ} \mathrm{C}$ ) (Martin-Vallejo et al. 1995). Only adult lizards (approximately SVL $>60 \mathrm{~mm}$ ) with complete tails were used in the experiment. Sex was determined based on intersexual differences in dorsal patterns of coloration. Given the high lizard density, and because we avoided sampling the same wall section twice, the probability of repeated sampling of the same individual was very low. We therefore treated all measurements as independent. Data of distances and times were log-transformed prior to analyses.

We used Pearson's correlations to examine the relationships between the variables that characterize escape behavior (approach and refuge distances and appearance time). We used two-way analysis of covariance (ANCOVA) to test whether the initial eye used before escaping affected approach distance after removing the effect of covariation with refuge distances. We used one-way ANOVA to test the effects of the first eye used on appearance times. These tests were calculated with the Statistica 6.0 for Windows ${ }^{\circledR}$ software (StatSoft Inc., Tulsa, OK, USA). We used the chi-square component ' $z$ ' index $(z)$ (Bishop et al. 1975) to compare the sample's total eye choice frequency with the relative expected frequency for left and right eye.

\section{Results}

We obtained data from 140 individual adult lizards (95 males and 45 females). When lizards were approached, 71 of them had the left eye oriented in the direction of the approaching experimenter and 69 had the right eye (initial eye, chi-square component ' $z$ ' index, $z=0.120, \mathrm{p}>0.05$ ) (males: 49 left $/ 46$ right, $z=0.218, \mathrm{p}>0.05$; females: $22 \mathrm{left} / 23 \mathrm{right}$, $z=0.105, \mathrm{p}>0.05)$. This suggested that the initial eye used depended on the relative position of the lizard on the wall and the experimenter position rather than on voluntary movements of the lizard after detecting the predator.

Approach distances of lizards ranged between 5 and $300 \mathrm{~cm}(\bar{x} \pm \mathrm{SE}=78 \pm 5 \mathrm{~cm})$, and distances to refuge ranged between 0 and $150 \mathrm{~cm}(\bar{x} \pm \mathrm{SE}=$ $18 \pm 2 \mathrm{~cm})$. Approach distances were significantly related to the distance to the refuge, such that lizards that were initially farther from the refuge had significantly longer approach distances (Pearson's correlation, $\quad r=0.40, \quad F=27.08, \quad \mathrm{df}=1138, \quad \mathrm{p}<$ $0.0001)$. The initial eye that the lizard was using before the attack did not have a significant effect on 
approach distances, after removing the effect of covariation with distance to refuge (ANCOVA, initial eye: $F=1.09, \mathrm{df}=1137, \mathrm{p}=0.30$; distance to refuge: $F=25.94, \mathrm{df}=1137, \mathrm{p}<0.0001)$. Appearance times from the refuge ranged between 3 and $96 \mathrm{~s}(\bar{x} \pm \mathrm{SE}=20 \pm 1 \mathrm{~s})$. Appearance times were not significantly related to the previous approach distances (Pearson's correlation, $r=-0.14, F=2.80$, $\mathrm{df}=1138, \quad \mathrm{p}=0.096)$ or distances to refuges $(r=-0.09, F=1.05, \mathrm{df}=1138, \mathrm{p}=0.31)$. The initial eye also did not significantly affect appearance times (one-way ANOVA, $F=0.59$, df $=1138, p=0.44$ ).

When the lizards decided to emerge from the refuge, they typically moved slowly toward the exit, emerged partially from the refuge (usually only the head, and always no more than half of the body) and turned the head or the entire body to scan outside with an eye before emerging totally. Lizards scanned with their left eye more often than their right eye; they scanned first using the left eye in 93 occasions and the right eye in 47 occasions (chi-square component ' $z$ ' index, $z=2.749$, $\mathrm{p}<0.01$; males: 64 left vs. 31 right, $z=2.394, p<0.01$; females: 29 left vs. 16 right, $z=1.370, p<0.05$ ) (Fig. 1). The eye used was the same during all the time until the lizard emerged entirely from the refuge in all but two cases where lizards changed their position inside the refuge before emerging.

The eye used to scan outside of the refuge was the same as the initial eye used before escaping in 75 occasions and the opposite one in 65 occasions $(z=0.598, \mathrm{p}>0.05)$.

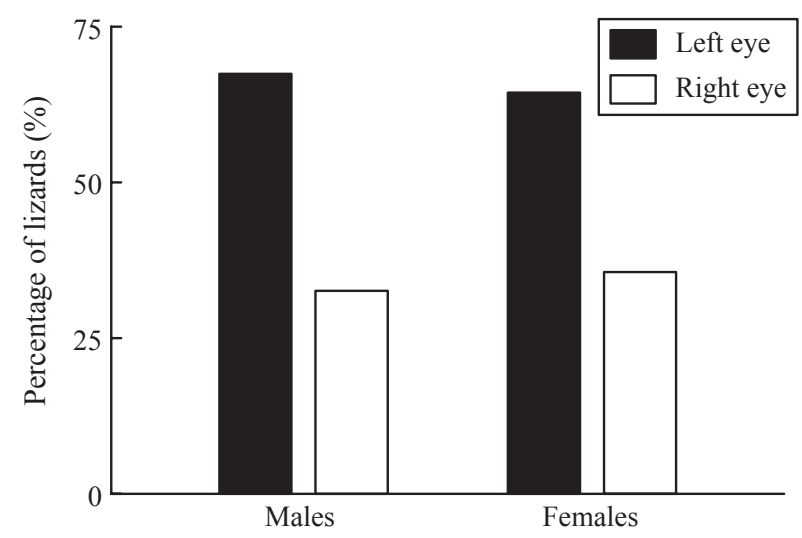

Fig. 1: Percentage of male $(n=95)$ and female $(n=45)$ common wall lizards (Podarcis muralis) that used the left (black boxes) or the right eye (open boxes) to monitor the predator in their first appearance from a refuge.

\section{Discussion}

Our results underline that $P$. muralis lizards showed a visual lateralization in antipredatory behavior in the field. In particular, when coming out from the refuge after a predatory attack, lizards preferred to monitor the predator with the left eye, thus processing antipredatory cues with the right brain hemisphere.

Field studies on lateralization are difficult to conduct because it is difficult to control the many physical and environment variables that could influence the behavior of the individuals studied. However, field studies may provide important support for laboratory data, revealing that lateralization occurs in nature and is not simply a laboratory artifact. To understand the fitness consequences of this trait, future research should test whether lizards monitor consistently with their left or right eye over multiple episodes. Then, it should be tested whether lizards that monitored with their left eye were better able to escape predators and survive than those that monitored with their right eye or with both eyes.

The random initial orientation of lizards when the experimenter approached may reflect that the initial position of the lizard was simply determined by the relative position of the lizard and the experimenter at the beginning of the attack. Hence, this orientation was independent of lateralization, but controlled by external variables. Moreover, because we approached lizards initially from a random left/right position relative to them, it may be confirmed that the preference shown in scanning with the left eye when they emerged from the refuge did not depend on the starting position of the lizards before escaping. This allows us to discard the possibility that there was an eventual environment influence of the eye choice when scanning in their first appearance from the refuge.

The approach distance was not dependent on the eye used in the first scan of the predator, but it was largely influenced by the distance to the nearest refuge. This suggests that escape decisions were not significantly affected by the eye that the lizards had initially available to watch the approaching predator and hence not guided by lateralization, but by the distance to refuge. In fact, this distance to refuge was more important in determining an optimal escape decision because it is likely indicative of the time it would take to reach a safe place (Ydenberg $\&$ Dill 1986; Cooper \& Frederick 2007a). Wall lizards, like many other animals, escape from predators with a short flight to the nearest available refuge (Lima \& 
Dill 1990; Martín \& López 1995, 2000; Cooper 1997c; Amo et al. 2003). Previous field studies showed that this nearest refuge may be previously known by the lizard (Amo et al. 2003) such that the escape response would be immediately directed to that refuge independently of the position of the predator. In this case, monitoring the predator before or during the short flight may not be as important as correctly estimating the optimal approach distance to escape in function of distance to available known refuges. However, sometimes prey have to escape for longer distances, often in open habitats without nearby safe refuges (Martín \& López 2000, 2003), or have more time to decide when to escape after monitoring a predator that has not yet launched an attack (Martín et al. 2009). In these circumstances, monitoring the predator while escaping, or while deciding when to escape, may be more important, and eye lateralization might have a more prominent role. In fact, when Sceloporus virgatus lizards are approached from directions impeding or preventing predator monitoring, approach distances are shorter than when approached from the side, which allows lizards to monitor the predator, establishing a benefit of monitoring on escape decisions (Cooper 2008). In a laboratory experiment, $P$. muralis lizards were attacked from behind and had to run for longer without the possibility of entering a refuge. In these circumstances, they needed to monitor the predator; so lizards escaped in a direction, the right one, which allowed watching and processing information on the predator with the left hemi-field (Bonati et al. 2010). In addition, in this laboratory experiment, when lizards stopped running and turned the head to monitor the predator, they preferentially used the left eye (Bonati et al. 2010). However, it remains to be analyzed whether there is also lateralization of the eye used by lizards to monitor the predator in the moments previous to escape.

The eye used by lizards when they were approached did not affect appearance time from the refuge. In this and many other ectothermic animals, time spent in refuges is dependent on risk level during the previous attack and on thermal conditions inside and outside the refuge (Amo et al. 2003; Martín \& López 2005). These variables determine the balance between costs and benefits of refuge use and lead to an optimal emergence time from the refuge (Sih 1997; Martín \& López 1999a,b; Cooper \& Frederick 2007b). Nevertheless, it would be interesting to test whether monitoring the predator with the preferred eye allowed a lizard to decrease the time needed to assess risk level. In fact, in other lacertid lizard species, uncertainty about the predator behavior during the first approach, and consequently about future risk, increases time spent by lizards scanning from the refuge before emerging (Polo et al. in press).

The eye used to scan the predator when appearing from the refuge changed in almost half of the sample with respect to the initial eye used when the experimenter approached. This result may reflect that the eye used voluntarily by the lizard to scan for the predator from the refuge was the preferred one for this task, independently of the previous field settings, whereas the initial eye used when approached was just randomly determined by the initial position of the lizard with respect to the experimenter. For this reason, the preferential use of the left eye for monitoring the predator from the refuge found in the field may be considered as a real indication of a visual bias that is not influenced by environmental confounding variables.

The direction of observation found is in accordance with and supports what was previously found in the same lizard species by Bonati et al. (2010) in experiments conducted in laboratory, as well as similar findings in other taxa (see Rogers \& Andrew 2002; MacNeilage et al. 2009 for reviews). Moreover, a similar eye bias was observed in an exploratory situation created in laboratory and conducted on the same lizard species. Here, individuals prefer using the left eye to look outside an open field while emerging from a box (Csermely et al., unpublished data). In fact, it is typical in lizards to look outside the refuge by turning the head or the body and using an eye for scanning before exiting (Cooper 2008; Polo et al. in press). Therefore, it is not surprising that this daily task, with important future fitness consequences, is guided from lateralization. Being lateralized could provide the advantage of more effectively monitoring the predator's presence or behavior outside the refuge, influencing lizards' emergence decision from refuges. On this basis, in a possible further individual analysis, and after controlling for other environmental variables, lateralized individuals might be expected to emerge sooner than non-lateralized ones, thus appearing bolder. Similarly, shorter refuge emergence times of lateralized individuals were found in the convict cichlid (Archocentrus nigrofasciatus), although Reddon \& Hurd (2009) attributed those differences to individual personalities. These results might suggest that the degree of individual lateralization might be one of the factors explaining shy-bold variation in antipredatory behavior of lizards (López et al. 2005). 
In our study area, we often observed active foraging predators known to eat this lizard (Martín \& López 1990), such as jays (Garrulus glandarius), magpies (Pica pica), great gray shrikes (Lanius excubitor), buzzards (Buteo buteo), short-toed eagles (Circaetus gallicus), kestrels (Falco tinnunculus) or little owls (Athene noctua), as well as abundant feral cats that frequently chased and killed these lizards in this and other populations (Boag 1973; Brown et al. 1995). Brown et al. (2007) found that a high predatory pressure could be important in increasing the number of lateralized individuals in a population. Similarly, the presence of a high predator pressure could have favored lateralization in this population of wall lizards.

\section{Acknowledgements}

We thank two anonymous reviewers for helpful comments and 'El Ventorrillo' MNCN Field Station for use of their facilities. This study benefited from the Financial support of the European Community, lst Programme Structuring the European Research Area, under SYNTHESYS, at Museo Nacional de Ciencias Naturales (CSIC), the Italian Ministero dell'Istruzione, Università e Ricerca, the Spanish Ministerio de Ciencia e Innovación project MCICGL2008-02119/BOS, and doctoral grants from the University of Parma to B.B. The experiments were conducted under license from the Environment Council of the Madrid Regional Government (Consejería de Medio Ambiente de la Comunidad de Madrid).

\section{Literature Cited}

Amo, L., López, P. \& Martín, J. 2003: Risk level and thermal costs affect the choice of escape strategy and refuge use in the wall lizard, Podarcis muralis. Copeia 2003, 899-905.

Amo, L., López, P. \& Martín, J. 2004: Thermal dependence of chemical assessment of predation risk affects the ability of wall lizards, Podarcis muralis, to avoid unsafe refuges. Physiol. Behav. 82, 913-918.

Andrew, R. J. 1991: The nature of behavioural lateralization in the chick. In: Neural and Behavioural Plasticity. The Use of the Chick as a Model (Andrew, R. J., ed.). Oxford Univ. Press, Oxford, pp. 536-554.

Bishop, Y. M. M., Fienberg, S. E. \& Holland, P. W. 1975: Discrete Multivariate Analysis. Theory and Practice. MIT Press, Cambridge and London.

Boag, D. A. 1973: Spatial relationships among members of a population of wall lizards. Oecologia 12, 1-13.
Bonati, B., Csermely, D. \& Romani, R. 2008: Lateralization in the predatory behaviour of the Common wall lizard (Podarcis muralis). Behav. Processes 79, $171-174$.

Bonati, B., Csermely, D., López, P. \& Martín, J. 2010 : Lateralization in the escape behaviour of the Common wall lizard (Podarcis muralis). Behav. Brain Res. 207, $1-6$.

Brown, R. F., Gist, D. H. \& Taylor, D. H. 1995: Home range ecology of an introduced population of the European wall lizard Podarcis muralis (Lacertilia; Lacertidae) in Cincinnati, Ohio. Am. Midl. Nat. 133, 344-359.

Brown, C., Western, J. \& Braithwaite, V. A. 2007: The influence of early experience on, and inheritance of, cerebral lateralization. Anim. Behav. 74, 231-238.

Burger, J. \& Gochfeld, M. 1993: The importance of the human face in risk perception by black iguanas, Ctenosaura similis. J. Herpetol 27, 426-430.

Cooper, W. E. Jr 1997a: Factors affecting risk and cost of escape by the broad-headed skink (Eumeces laticeps): predator speed, directness of approach, and female presence. Herpetologica 53, 464-474.

Cooper, W. E. Jr 1997b: Threat factors affecting antipredator behavior in the broad-headed skink (Eumeces laticeps): repeated approach, change in predator path, and predator's field of view. Copeia 1997, 613-619.

Cooper, W. E. Jr 1997c: Escape by a refuging prey, the broad-headed skink (Eumeces laticeps). Can. J. Zool. 75, 943-947.

Cooper, W. E. Jr 1998: Risk factors and emergence from refuge in the lizard Eumeces laticeps. Behaviour 135, 1065-1076.

Cooper, W. E. Jr 2008: Visual monitoring of predators: occurrence, cost and benefit for escape. Anim. Behav. 76, 1365-1372.

Cooper, W. E. Jr \& Frederick, W. G. 2007a: Optimal flight initiation distance. J. Theor. Biol. 244, 59-67.

Cooper, W. E. Jr \& Frederick, W. G. 2007b: Optimal time to emerge from refuge. Biol. J. Linn. Soc. 91, 375-382.

Cooper, W. E. Jr, Martín, J. \& López, P. 2003: Simultaneous risks and differences among individual predators affect refuge use by a lizard, Lacerta monticola. Behaviour 140, 27-41.

Csermely, D., Bonati, B., López, P. \& Martín, J. In press: Is the Podarcis muralis lizard left-eye lateralized when exploring a new environment? Laterality

Dadda, M. \& Bisazza, A. 2006: Does brain asymmetry allow efficient performance of simultaneous tasks? Anim. Behav. 72, 523-529.

Deckel, A. W. 1995: Laterality of aggressive response in Anolis. J. Exp. Zool. 272, 194-200.

Dharmaretnam, M. \& Rogers, L. J. 2005: Hemispheric specialization and dual processing in strongly versus 
weakly lateralized chicks. Behav. Brain Res. 162, $62-70$.

Fabre-Thorpe, M., Fagot, J., Lorincz, E., Levesque, F. \& Vauclair, J. 1993: Laterality in cats: paw preference and performance in a visuomotor activity. Cortex 29 , $15-24$.

Güntürkün, O. \& Kesh, S. 1987: Visual lateralization during feeding in pigeons. Behav. Neurosci. 101, 433-435.

Koboroff, A., Kaplan, G. \& Rogers, L. J. 2008: Hemispheric specialization in Australian magpies (Gymnorhina tibicen) shown as eye preferences during response to a predator. Brain Res. Bull. 76, 304-306.

Levy, J. 1977: The mammalian brain and the adaptive advantage of cerebral asymmetry. Ann. N. Y. Acad. Sci. 299, 264-272.

Lima, S. L. 1994: On the personal benefits of vigilance. Anim. Behav. 54, 1147-1154.

Lima, S. L. \& Dill, L. M. 1990: Behavioral decisions made under the risk of predation: a review and prospectus. Can. J. Zool. 68, 619-640.

Lippolis, G., Westman, W., McAllan, B. \& Rogers, L. 2002: Lateralization of predator avoidance responses in three species of toads. Laterality 7, 163-183.

Lippolis, G., Joss, J. M. P. \& Rogers, L. J. 2009: Australian lungfish (Neoceratodus forsteri): a missing link in the evolution of complementary side biases for predator avoidance and prey capture. Brain Behav. Evol. 73, 295-303.

López, P., Hawlena, D., Polo, V., Amo, L. \& Martín, J. 2005: Sources of individual shy-bold variations in antipredatory behaviour of male Iberian rock-lizards. Anim. Behav. 69, 1-9.

MacNeilage, P. F., Rogers, L. J. \& Vallortigara, G. 2009: Origins of the left $\delta$ right brain. Sci. Am. 301, 60-67.

Martín, J. \& López, P. 1990: Amphibians and reptiles as prey of birds in southwestern Europe. Smiths. Herpetol. Inf. Serv. 82, 1-43.

Martín, J. \& López, P. 1995: Influence of habitat structure on escape tactics of the lizard Psammodromus algirus. Can. J. Zool. 73, 129-132.

Martín, J. \& López, P. 1999a: When to come out from a refuge: risk-sensitive and state-dependent decisions in an alpine lizard. Behav. Ecol. 10, 487-492.

Martín, J. \& López, P. 1999b: An experimental test of the costs of antipredatory refuge use in the wall lizard, Podarcis muralis. Oikos 84, 499-505.

Martín, J. \& López, P. 2000: Fleeing to unsafe refuges: effects of conspicuousness and refuge safety on the escape decisions of the lizard Psammodromus algirus. Can. J. Zool. 78, 265-270.

Martín, J. \& López, P. 2001: Repeated predatory attacks and multiple decisions to come out from a refuge in an alpine lizard. Behav. Ecol. 12, 386-389.
Martín, J. \& López, P. 2003: Changes in the escape responses of the lizard Acanthodactylus erythrurus under persistent predatory attacks. Copeia 2003, 408-413.

Martín, J. \& López, P. 2005: Wall lizards modulate refuge use through continuous assessment of predation risk level. Ethology 111, 207-219.

Martín, J., Luque-Larena, J. J. \& López, P. 2009: When to run from an ambush predator: balancing crypsis benefits with costs of fleeing in lizards. Anim. Behav. 78, $1011-1018$.

Martin-Vallejo, J., García-Fernández, J., Pérez-Mellado, V. \& Vicente-Villardón, J. L. 1995: Habitat selection and thermal ecology of the sympatric lizards Podarcis muralis and Podarcis hispanica in a mountain region of central Spain. Herpetol. J. 5, 181-188.

McGrew, W. C. \& Marchant, L. F. 1999: Laterality of hand use pays off in foraging success for wild chimpanzees. Primates 40, 509-513.

Miklósi, A. \& Andrew, R. J. 1999: Right eye use associated with decision to bite in zebrafish. Behav. Brain Res. 105, 199-205.

Polo, V., López, P. \& Martín, J. (in press): Uncertainty about future predation risk modulates monitoring behaviour from refuges in lizards. Behav. Ecol., in press.

Reddon, A. R. \& Hurd, P. L. 2009: Individual differences in cerebral lateralization are associated with shy-bold variation in the convict cichlid. Anim. Behav. 77, 189-193.

Robins, A. 2006: Lateralized visual processing in anurans: new vistas though ancient eyes. In: Behavioral and Morphological Asymmetries in Vertebrates (Malashichev, Y. B., Deckel, A. W., eds). Landes Bioscience, Georgetown, pp. 86-106.

Robins, A. \& Rogers, L. J. 2004: Lateralized prey-catching responses in the cane toad, Bufo marinus: analysis of complex visual stimuli. Anim. Behav. 68, 567-575.

Rogers, L. J. 1997: Early experiential effects on laterality: research on chicks has relevance to other species. Laterality 2, 199-219.

Rogers, L. J. 2002: Advantages and disadvantages of lateralization. In: Comparative Vertebrate Lateralization (Rogers, L. J. \& Andrew, R. J., eds). Cambridge Univ. Press, Cambridge, pp. 9-69.

Rogers, L. J. \& Andrew, R. J. 2002: Comparative Vertebrate Lateralization. Cambridge Univ. Press, Cambridge.

Rogers, L. J., Zucca, P. \& Vallortigara, G. 2004: Advantages of having a lateralized brain. Proc. R. Soc. Lond. B 271, S420-S422.

Röll, B. 2001: Retina of Bouton's skink (Reptilia, Scincidae): visual cells, fovea, and ecological constraints. J. Comp. Neurol. 436, 487-496.

Sherry, D. F. \& Schachter, D. L. 1987: The evolution of multiple memory systems. Psychol. Rev. 94, 439—454. 
Sih, A. 1997: To hide or not to hide? Refuge use in a fluctuating environment. Trends Ecol. Evol. 12, 375-376.

Sovrano, V. A., Dadda, M. \& Bisazza, A. 2005: Lateralized fish perform better than nonlateralized fish in spatial reorientation tasks. Behav. Brain Res. 163, 122-127.

Vallortigara, G. 2000: Comparative neuropsychology of the dual brain: a stroll through left and right animals' perceptual world. Brain Lang. 73, 189-219.

Vallortigara, G. \& Rogers, J. L. 2005: Survival with asymmetrical brain: advantages and disadvantages of cerebral lateralization. Behav. Brain Sci. 28, 575-633.

Vallortigara, G., Rogers, L. J., Bisazza, A., Lippolis, G. $\delta$ Robins, A. 1998: Complementary right and left hemi- field use for predatory and agonistic behaviour in toads. Neuroreport 9, 3341-3344.

Ventolini, N., Ferrero, E. A., Sponza, S., Della Chiesa, A., Zucca, P. \& Vallortigara, G. 2005: Laterality in the wild: preferential hemifield use during predatory and sexual behaviour in the black-winged stilt. Anim. Behav. 69, 1077-1084.

Wright, J. W., Berg, E., De Kort, S. R., Khazin, V. \& Maklakov, A. A. 2001: Cooperative sentinel behaviour in the Arabian babbler. Anim. Behav. 62, 973-979.

Ydenberg, R. C. \& Dill, L. M. 1986: The economics of fleeing from predators. Adv. Study Behav. 16, 229-249. 